【論文】

\title{
サーマルマイクロスコープによる 熱浸透率の簡便な校正方法 \\ A simple calibration procedure to determine thermal effusivity values measured by using a thermal microscope
}

\author{
羽鳥仁人*、太田弘道** \\ Kimihito Hatori, Hiromichi Ohta
}

\begin{abstract}
サーマルマイクロスコープは熱輸送指数の局所的な分布を測定するために有効な装置である。しか し従来の一次元熱伝導のみを仮定した解析法では、熱浸透率の高い材料については実際の值より大き な值が得られることが知られていた。我々は、熱物性值の知られている複数の基準試料を用いた簡便 な校正方法を開発した。温度応答には厳密には熱浸透率だけでなく試料の体積熱容量も影響を与える 可能性がある。しかし体積熱容量の影響を考慮せずその值が異なる基準試料を使ったにもかかわらず、 熱浸透率のみを考えた方法で校正することにより純鉄の測定值は一次元熱伝導を仮定した解析式に より求めた值に比べて文献值に近い值が得られた。この結果から、この測定方法は熱浸透率の簡便な 校正方法として有効であることが分かった。
\end{abstract}

A thermal microscope is a useful tool for investigating the spatial distribution of the thermal transport properties of materials. However, for materials with relatively high thermal effusivities, it is well known that the values calculated on the basis of the conventional one-dimensional heat flow solution are higher than the values provided in the literature. In this study, we developed a simple calibration procedure for a thermal microscope to measure the thermal effusivities of materials by using several reference materials whose thermal effusivities are known. It is expected that the temperature response will be influenced by not only the thermal effusivity but also the heat capacity per unit volume. However, reference samples with different heat capacities per unit volume were used. In comparison with the calculated values obtained with the conventional one-dimensional heat flow solution, the values for pure iron obtained with our calibration procedure, without considering the heat capacity per unit volume, were closer to the values provided in the literature. We found that this procedure is useful for calibrating a thermal microscope easily for measuring thermal effusivity.

[Keywords: thermoreflectance, periodical heating, calibration, thermal microscope, thermal effusivity]

\section{INTRODUCTION}

Highly reliable thermal properties of materials at the microscale level are important in thermal design techniques for the development of magnetic heads, optical disks, and coatings for thermal barriers. The development of nanotechnology has led to the miniaturization of materials, which is demonstrated by the densification of integrated circuits with narrower pattern line widths.

* 茨城大学工学部物質工学科 博士後期課程、 市 中成沢町 4-12-1. Graduate School, Department of Material Science, Ibaraki University, Hitachi 316-8511. FAX: 0299-36-0691 E-mail: k-hatori@bethel.co.jp

** 茨城大学工学部物質工学科、 $\overline{1} 316-8511$ 日立市 中成沢町 4-12-1. Department of Material Science, Ibaraki University, Hitachi 316-8511.

FAX: 0294-38-5226 E-mail: ohta@mx.ibaraki.ac.jp
However, with increase in the density of integration, the heat dissipation from such microdevices with nano -structures has become a critical issue in thermal design techniques. In order to enhance the functionality of the nanostructures in heat transfer, it is necessary to develop a technology that will enable a quantitative evaluation of the thermal transport properties of microscale areas. However, it is generally difficult to measure the thermal transport properties of microscale areas because of the considerably low thermal resistance across a small sample, which results in an extremely short time constant for heat dissipation. Due to such characteristics of microscale areas, a fast transient method, which is represented by the thermo-reflectance method, has been developed recently and is being widely used. 
In the fast transient method, high-speed temperature measurement is the key technology because heat diffuses into microscale areas in an extremely short amount of time. In addition, rapid heating for measurements must be applied uniformly over the surface of the target region in order to obtain a uniform spatial distribution of the properties. Hence, the heat is generally applied by using a periodically modulated laser driven by a high-frequency or a short-pulse laser. In the thermoreflectance method, the change in temperature of a metallic sample is measured at a high speed by detecting the reflectivity of the surface, which generally varies with temperature. The change in reflectivity is measured by irradiating a laser beam (a probe laser) of constant power on the metal surface and measuring the intensity of the reflected light. If a fast photodiode is used to detect the reflected light, this method enables the measurement of the change in temperature with high time resolutions as compared to those provided by conventional measuring instruments such as infrared radiation thermometers and thermo -couples. The measurements at high spatial resolutions are acquired by using probe lasers that are more condensed. In this study, the measurements of microscale areas have been conducted by using a technique based on the thermoreflectance method explained above.

The measurement of the thermal properties of micro -scale areas was first developed by Rosencwaig; this method enables the evaluation of the surface and subsurface defects in a semiconductor by using thermal waves $[1,2]$. Pottier developed a micrometer scale visualization method [3] in which the spatial distribution of thermal diffusivity is derived from the contour lines of the amplitude and phase lag of the reflected light by scanning a heating laser while the sample and the probe laser are fixed during the measurement. Lepoutre et al. [4] proposed a laser-induced photoreflectance method for measuring the thermal diffusivities and the quality of interfaces in composite materials. They also measured the thermal diffusivity derived from the contour lines of the phase lag by scanning the probe laser while the sample and the heating laser were fixed. Further, they suggested that both the lasers must be fixed at a particular location in order to detect local clacks that may cause high thermal resistance. Haxtable et al., [5] Costescu et al., [6], and O'Hara et al. [7] developed a measurement method to obtain the distribution of thermal conductivity on a small surface at the micrometer scale by using a time-domain thermoreflectance method. This method uses two synchro -nous short-pulse lasers, which are used to heat the sample surface and measure the resulting change in the reflectivity of the metal surface.

Taketoshi et al. developed a thermal microscope for commercial use for determining the thermal properties of a material at the microscale level. Their apparatus uses an inexpensive semiconductor laser to produce a heating beam and a probe beam and also realizes high spatial resolution by combining high-speed periodic heating with temperature detection by the thermo-reflectance method. [8-16]

When the conventional one-dimensional heat flow solution is assumed for the calculation of thermal effusivity from the data measured with a thermal microscope, the values of the thermal effusivities of the samples with relatively low thermal conductivities, such as Pyrex glass and Glassy carbon, exhibit close agreement with the values provided in the literature. However, the same calculation method produced higher values of effusivity as compared to the values provided in the literature for metals with relatively high thermal conductivities. This discrepancy between the values in the literature for regions with higher thermal conductivity is considered to be caused by the effect of a two -dimensional heat flow, which is not considered in the conventional one-dimensional model [12]. This assump -tion was also confirmed experimentally. Okamura et al. [16] prepared thermally isolated islands on the surfaces of Pyrex and silicon samples, which were shaped into a rectangular pattern with dimensions of $2 \mu \mathrm{m} \times 5 \mu \mathrm{m}$ and surrounded by a ditch, in order to decrease the thermal diffusion parallel to the sample surface. They measured the phase lag of the light reflected on the surface of the island and estimated the effect of the two-dimensional heat flow. The results showed that with decrease in the area of an "island", the measured thermal effusivity 
reaches a value that is closer to the value expressed by assuming the conventional one-dimensional heat flow model [16]. When the heat flow is considered to be purely one-dimensional, the thermal effusivity values are calculated by a simple analytical procedure [8]. When the one-dimensional heat flow model is invalid, the thermal effusivity values must be calculated by a numerical or an analytical procedure, which considers the effect of the two-dimensional heat flow. Although these methods provide accurate results, the calculation procedures are generally much more complicated than those of the conventional one-dimensional heat flow model. In order to simplify this procedure, we have developed a simplified and practical procedure to calibrate the thermal microscope in order to obtain the thermal effusivity values by considering the effect of the two-dimensional heat flow. This paper describes the basic principle of the procedure with several experimental results.

\section{MEASUREMENT PRINCIPLE AND EXPERIMENT}

The basic principle and the experimental procedure to measure thermal effusivity by using a thermal microscope has been described elsewhere in detail $[8,11,13,14]$. Therefore, only some essential features of this technique are explained as follows.

Figure 1 shows a schematic view of the experimental device near the sample. A heating laser beam is irradiated on the sample surface. The heating laser is modulated by a sinusoidal wave, and therefore the heat flux $Q(t)$ on the sample surface induced by the laser is expressed as follows:

$Q(t)=Q_{0} \sin \omega t$

Here, $\omega$ represents the modulation angular frequency of a heating laser, and $t$ represents the time. An alternating current component of the surface temperature response $T(t)$ is expressed in the steady state, as follows:

$T(t)=T_{0} \sin (\omega t-\delta)$ $\delta=\frac{3}{4} \pi+\arctan \left(\frac{\cosh ^{2} \sqrt{\frac{\omega \tau_{f}}{2}}\left(\tanh \sqrt{\frac{\omega \tau_{f}}{2}}+\beta\right)}{\cos ^{2} \sqrt{\frac{\omega \tau_{f}}{2}}\left(\beta-\beta^{-1}\right)}\right.$
$\left.\frac{\left(\tanh \sqrt{\frac{\omega \tau_{f}}{2}}+\beta^{-1}\right)}{\tan \sqrt{\frac{\omega \tau_{f}}{2}}}\right)$
Here,

$\tau_{f}=d^{2} / \alpha_{f}=d^{2} \rho_{f} C_{f} / \lambda_{f}=d^{2} \rho_{f}{ }^{2} C_{f}{ }^{2} / b_{f}{ }^{2}$

$\beta=\frac{b_{s}}{b_{f}}=\frac{\sqrt{\lambda_{s} \rho_{s} C_{s}}}{\sqrt{\lambda_{f} \rho_{f} C_{f}}}$

$\delta$ represents the phase lag of a surface temperature response for a periodic heating by the laser; $d$, the thickness of a metal film on the sample; $\alpha_{f}$, the thermal diffusivity of the film; and $\tau_{f}$, the characteristic time for the thermal diffusion in the film. The subscripts f and s imply the metal film and the sample, respectively. The thermal effusivity $b_{s}$ of the sample is obtained from equations (3), (4), and (5) if the phase lag $\delta$ is measured and the thermal effusivity of the metal film is known.

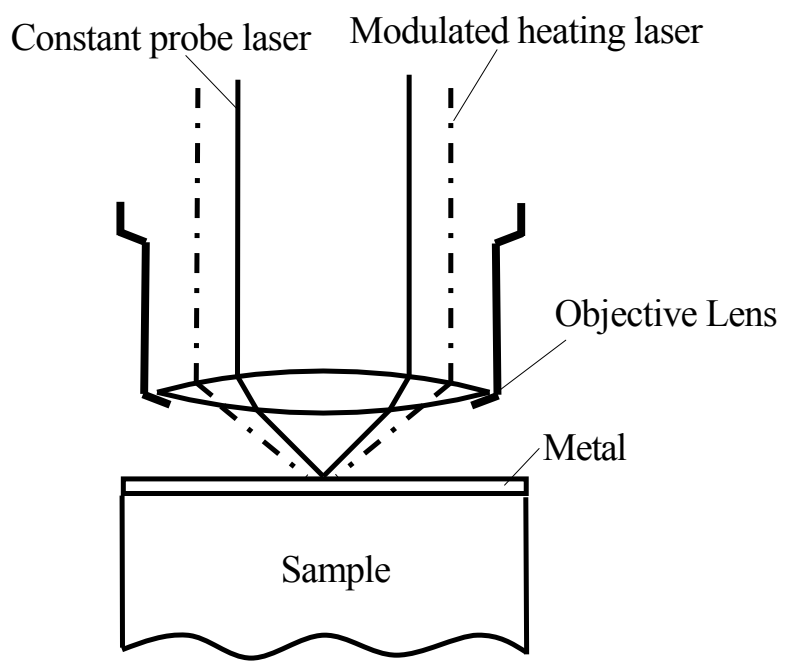

Fig.1. Schematic diagram of the sample assembly employed in this study.

A functional diagram of a thermal microscope is shown in figure 2. The heating laser and the probe laser are irradiated at the same position on the sample by using 
microscope optics. By scanning the laser spot, the measurement of the thermal effusivity distribution is performed. A semiconductor laser was used to produce the heating laser beam with a wavelength of $830 \mathrm{~nm}$, and an effective irradiation power of $16 \mathrm{~mW}$. The beam spot on the sample surface was oval in shape with a major axis of $26 \mu \mathrm{m}$ and a minor axis of $9 \mu \mathrm{m}$. The intensity of the heating laser was modulated by a signal from a function generator with a frequency of $1 \mathrm{MHz}$. Another semi -conductor laser, with a wavelength of $655 \mathrm{~nm}$ and an irradiation power of $0.6 \mathrm{~mW}$, was used as the probe laser; the resulting beam spot was a circular area with a diameter of $7 \mu \mathrm{m}$. The two laser lights with different wavelengths reflected by the metal film on the sample were transmitted to a photo detector by a half mirror. The heating laser was intercepted by a band-pass filter in front of the detector and only the intensity of the reflected probe laser was measured with the photo detector by using a silicon photodiode. By using the reference signal from a function generator, which modulates the heating laser as a synchronization input, the phase difference $\delta_{p}$ between the probe laser and the reference signal of the function generator is measured. Then, under the same conditions, the phase difference $\delta_{h}$ between the reference signal of the function generator and the heating laser is determined. The phase lag $\delta$ between the surface temperature response and the heating laser is given by

$\delta=\delta_{p}-\delta_{h}$

\section{CALIBRATION METHOD USING REFERENCE SAMPLES}

In this study, the calibration of the thermal microscope for correcting the effect of the two-dimensional heat flow has been performed by defining a calibration curve for the measured results on the reference samples. The procedure for the correction is as follows. The four reference samples_-7740 Pyrex glass, titanium, silicon nitride, and silicon - with known thermal effusivities are prepared. A molybdenum film with a thickness of $100 \mathrm{~nm}$ is coated on the surface of each material by sputtering. Table 1 lists the thermal properties of the reference samples provided in the literature $[17,18]$.

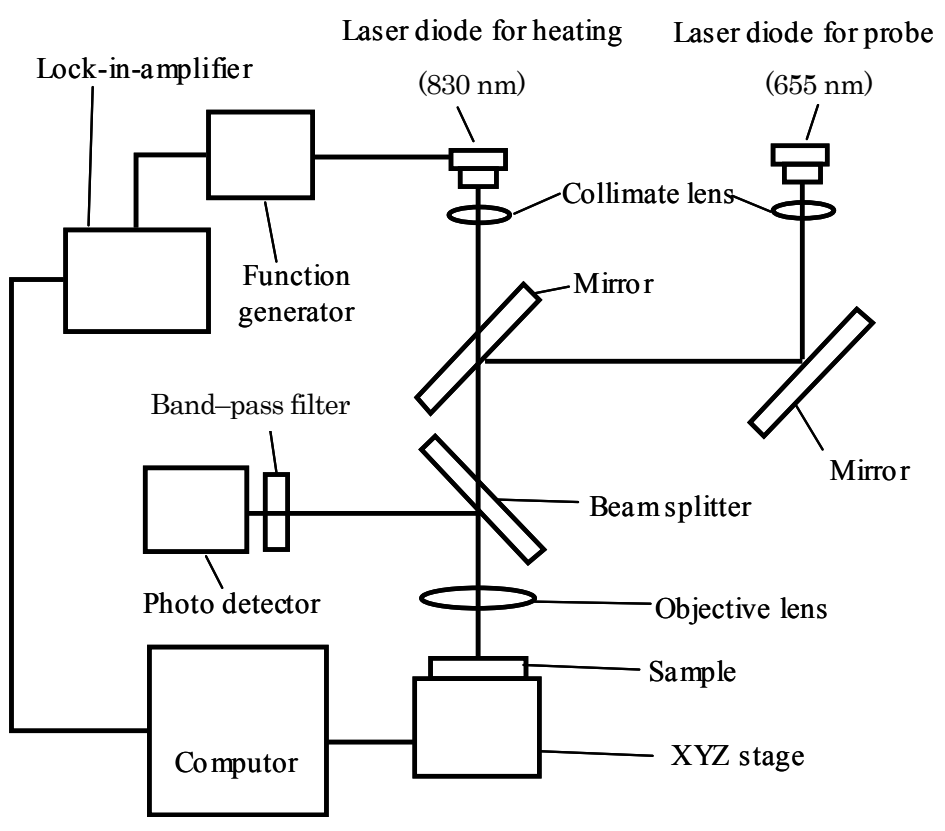

Fig.2. Schematic diagram of the measurement apparatus.

Table 1. Thermal properties of the reference samples [17].

\begin{tabular}{lcccc}
\hline Sample & $\begin{array}{c}\lambda \\
\mathrm{Wm}^{-1} \mathrm{~K}^{-1}\end{array}$ & $\begin{array}{c}C \\
\mathrm{Jkg}^{-1} \mathrm{~K}^{-1}\end{array}$ & $\begin{array}{c}\rho \\
\mathrm{kgm}^{-3}\end{array}$ & $\begin{array}{c}b \\
\mathrm{Js}^{-0.5} \mathrm{~m}^{-2} \mathrm{~K}^{-}\end{array}$ \\
\hline $\begin{array}{l}\text { Pyrex } \\
7740\end{array}$ & 1.1 & 730 & 2,230 & 1,340 \\
\hline Titanium & 21.9 & 522 & 4,506 & 7,180 \\
\hline $\begin{array}{l}\text { Silicon } \\
\text { nitride }\end{array}$ & $39.2[18]$ & 711 & 3,210 & 9,460 \\
\hline Silicon & 148 & 713 & 2,330 & 15,700 \\
\hline
\end{tabular}

The phase lag $\delta$ was measured for these samples by using a thermal microscope. The power of the heating laser was constant for all the samples. By using the measured data on the reference samples, we defined a calibration curve to express the relationship between $b$ and $\delta$. After the calibration curve was defined, we used this curve in order to obtain the thermal effusivities of the unknown samples. Figure 3(a) shows the measured results in which the thermal effusivity $b$ of the reference samples are plotted against the phase lag $\delta$. In these results, the thermal effusivity $b$ is approximated by defining a calibration curve expressed by a cubic equation $b=C_{0}+$ $C_{1} \delta+C_{2} \delta^{2}+C_{3} \delta^{3}$ as a function of the phase lag $\delta$. We defined the values of $C_{0}, C_{1}, C_{2}$, and $C_{3}$ by using the least-squares method. This calibration curve is expressed 
in the form of equation (7).

$b=16,720+664.4 \delta-36.42 \delta^{2}+0.3512 \delta^{3}$

In addition, we have shown the values of thermal effusivity calculated by equations (3), (4), and (5) by a dashed line in figure 3(a) to indicate the result based on the one-dimensional heat flow model. The thermal diffusivity value of molybdenum thin films provided in the literature [19] was used as the thermal diffusivity of the molybdenum film required to calculate the thermal effusivity of the sample. The film was deposited under conditions similar to those in the present study. In addition, the specific heat and the density of molybdenum were obtained from the values of the bulk sample provided in the literature.

Since the power of the heating laser is maintained constant for all samples, the signal amplitude of the surface temperature generally decreases as the thermal effusivity of the sample increases. Since the intensity of noise does not depend on the sample, the signal/noise ratio of the temperature signal falls according to the increase in thermal effusivity. In this measurement, one data point represents a mean value of 100 samples with a standard deviation of $\sigma$. Therefore, we determined the standard deviation of uncertainty for the measured value of $b$ by using equation (7) from the $\sigma$ measured at the four data points corresponding to the four reference samples. From these values of $\sigma$, an approximate linear equation, $\sigma=C_{4}+C_{5} \quad \delta$, was derived as a function of phase lag $\delta$ by using the values of $C_{4}$ and $C_{5}$ obtained by the least-squares method. The standard deviation of uncertainty calculated by equation (8) is shown in figure 3(b).

$\sigma=-51.2 \delta+2,912.5$

In addition, for the sample with high thermal diffusivity, the effective area of the sample surface over which the temperature variations occur increases due to thermal diffusion. In other words, the two-dimensional heat flow reduces the spatial resolution of a thermal microscope. The reduction in the spatial resolution due to the two-dimensional heat flow can be estimated by considering the thermal diffusion length. When the two-dimensional heat flow is negligible, the spatial resolution is identical to the diameter of the probe laser. When the thermal effusivity of a sample is high, the thermal wave spreads in a two- dimensional manner from the heated surface. Therefore, the estimation of the total spatial resolution results in the determination of the sum of the diameter of the probe laser and twice the thermal diffusion length. The spatial resolution $D_{0}$ of a thermal microscope can be calculated by using the following equations:

$D_{0}=\mu+2 D_{1}$

$D_{1}=\frac{b}{\rho_{s} C_{s} \sqrt{2 \pi \omega}}=\frac{c_{0}+c_{1} \delta+c_{2} \delta^{2}+c_{3} \delta^{3}}{\rho_{s} C_{s} \sqrt{2 \pi \omega}}$

$D_{1}$ represents an increased value of the radius of the spatial resolution due to the effect of the two-dimensional thermal diffusion, which corresponds to the thermal diffusion length; $\mu$, the diameter of probe laser; $\omega$, the modulation angular frequency of the heating laser beam; $b$, the thermal effusivity; $\rho$, the density; and $C$, the specific heat capacity of the sample.

Figure 3(c) shows the relationship between the phase lag and spatial resolution calculated by using equation (9). The heat capacity of a unit volume $\rho C$, which is necessary to calculate the spatial resolution, generally ranges from $4.0 \times 10^{5}$ to $4.0 \times 10^{6} \mathrm{Jm}^{-3} \mathrm{~K}^{-1}$ for solid dense bulk materials at room temperature. In the calculation shown in figure 3(c), $\rho C$ is assumed to be $2.3 \times$ $10^{6} \mathrm{Jm}^{-3} \mathrm{~K}^{-1}$. This value is estimated by the heat capacity per unit volume of the pure materials [17]. In these measurements, the modulation frequency of the heating laser is $1 \mathrm{MHz}$, and the diameter of the probe laser, which corresponds to the intrinsic spatial resolution of the apparatus, is $7 \mu \mathrm{m}$.

From the phase lag measured by using the thermal microscope, we determined the thermal effusivity, standard deviation, and spatial resolution of a sample with unknown properties by using the calibration curves shown in figure 3. 


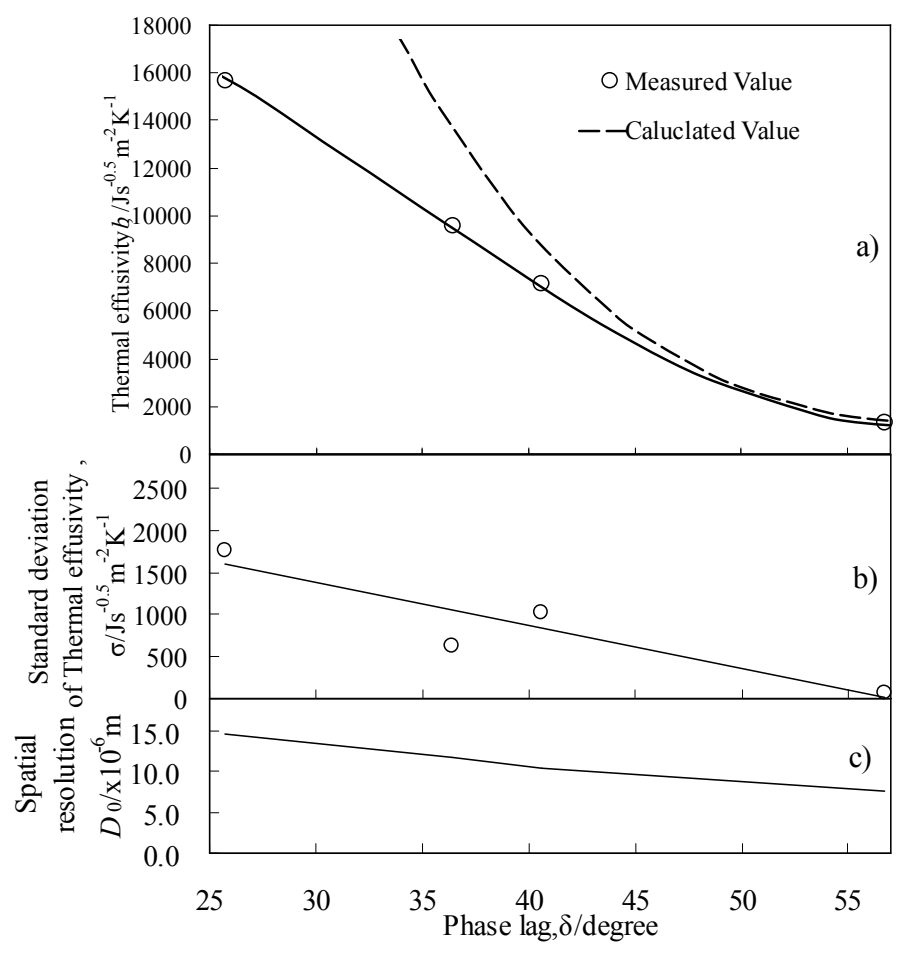

Fig.3. Calibration curves as a function of phase lag determined by the measurement of the reference samples (a) thermal effusivity, (b) standard deviation, and (c) spatial resolution calculated for the sample with $\rho C=2.3 \times 10^{6} \mathrm{Jm}^{-3} \mathrm{~K}^{-1}$.

\section{MEASUREMENT RESULT AND DISCUSSIONS}

Figures 4(a) and (b) show the thermal effusivity distribution over an intersection perpendicular to the surface of a functionally grated material (thickness of 800 $\mu \mathrm{m})$ consisting of an intermetallic compound between $\mathrm{Al}_{3} \mathrm{Ti}$ and $\mathrm{Fe}$ measured with the present technique. Figure 4(a) shows the distribution across the intersection between $\mathrm{Al}_{3} \mathrm{Ti}$ and $\mathrm{Fe}$ perpendicular to the surface and 4(b) shows the spatial distribution over the intersection. The composi -tion ratio of the two materials was functionally graded from the rear surface to the top surface for better heat resistance and corrosion resistance [20]. Figure 5 shows the distribution of iron over the intersection of the $\mathrm{Al}_{3} \mathrm{Ti}$ and $\mathrm{Fe}$ measured with a method based on energy dispersion X-ray spectrometry. The white line indicates the analyzed concentration of iron across the intersection. The iron composition increases continually from the right-hand side to the left-hand side on the figure.
In figures 4 (a) and (b), it is observed that the thermal effusivity of the functionally graded material gradually decreases from the pure iron region to the $\mathrm{Al}_{3} \mathrm{Ti}$ region according to the change in composition. The value of the thermal effusivity of the bulk iron provided in the literature is $16,700 \mathrm{Js}^{-0.5} \mathrm{~m}^{-2} \mathrm{~K}^{-1}$ [12]. The present measured value of thermal effusivity for the substrate in the region of pure iron is $19,200 \pm 1,900 \mathrm{Js}^{-0.5} \mathrm{~m}^{-2} \mathrm{~K}^{-1}$; this value almost agrees with the value provided in the literature. In the region of the pure intermetallic compound $\mathrm{Al}_{3} \mathrm{Ti}$, the measured value is 8,400 $\mathrm{Js}^{-0.5} \mathrm{~m}^{-2} \mathrm{~K}^{-1}$.

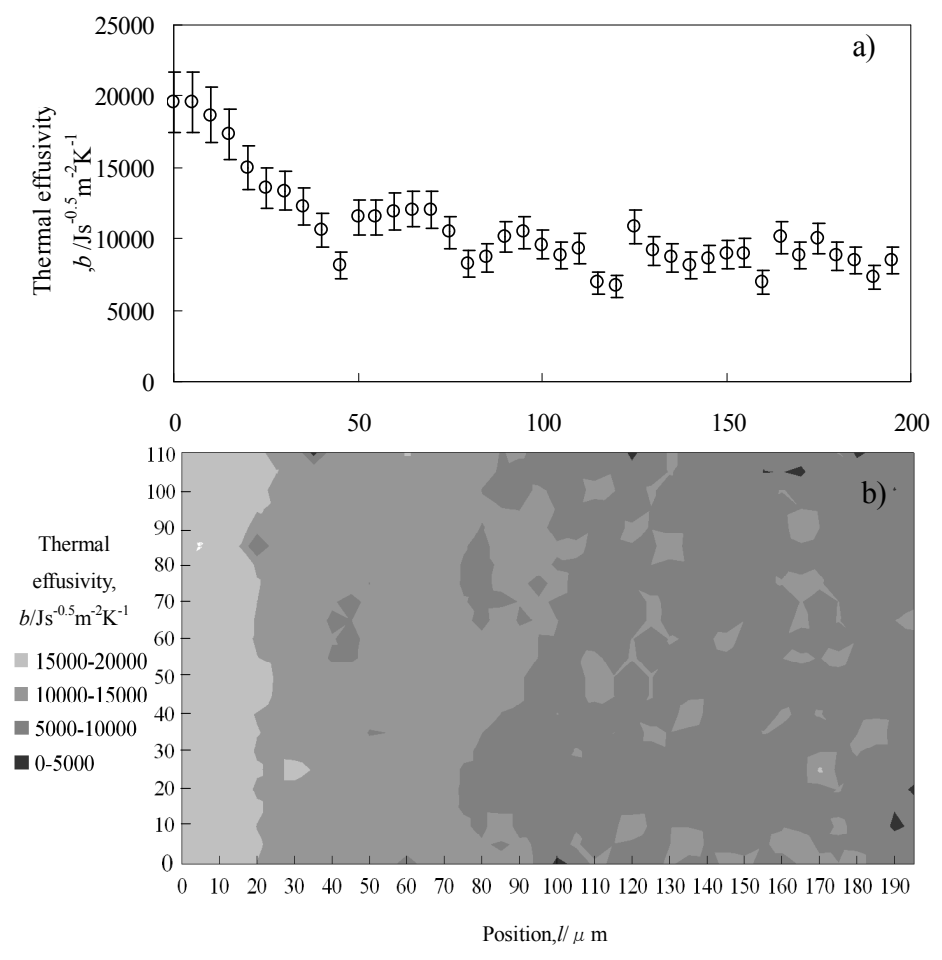

Fig.4. Thermal effusivity distribution over the intersection of a functionally graded material made of the intermetallic compound $\mathrm{Al}_{3} \mathrm{Ti}$ and $\mathrm{Fe}$

(a) Line analysis across the intersection

(b) Contour line mapping over the intersection

We compared this value with that obtained by using the conventional analytical method in which the effects of two-dimensional heat flow are not considered. In the case of the intermetallic compound $\mathrm{Al}_{3} \mathrm{Ti}$, the conventional analytical method yielded a value of $11,500 \mathrm{Js}^{-0.5} \mathrm{~m}^{-2} \mathrm{~K}^{-1}$ [12]; this value is approximately 1.4 times greater than 
that obtained by the present method. In the case of iron, the value obtained with the conventional analytical method was $54,700 \mathrm{Js}^{-0.5} \mathrm{~m}^{-2} \mathrm{~K}^{-1}$ [12], which is approximately 2.8 times greater than that obtained with the present method. We consider that these results in comparison with the values provided in the literature clarify the validity of the present method.

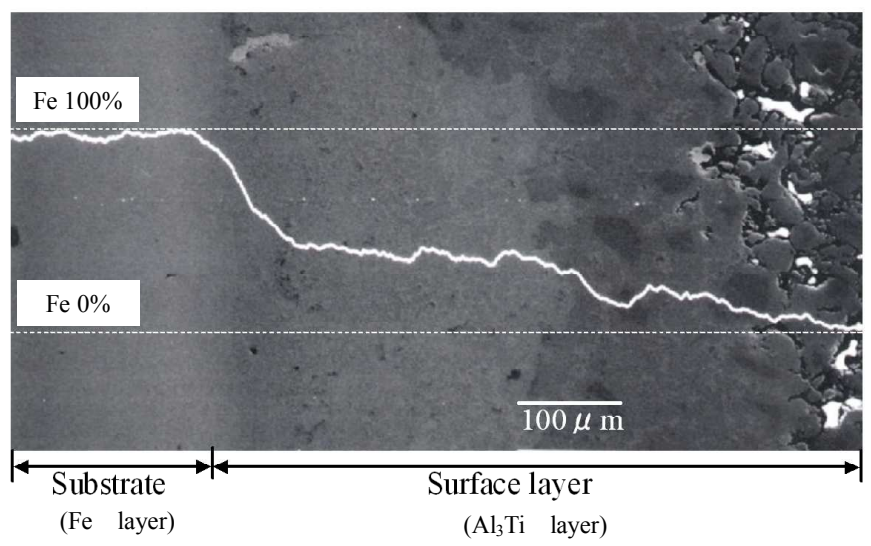

Fig.5. Composition distribution of $\mathrm{Al}_{3} \mathrm{Ti} / \mathrm{Fe}$ functionally graded material measured with energy dispersive $\mathrm{X}$-ray spectroscopy. The white line represents the iron concentration, whose composition increases continually from the right-hand side to the left-hand side on the figure.

\section{CONCLUSION}

A thermal microscope is a promising instrument to quantitatively measure the thermal properties of a small material in a microscale area. Analytical data processing methods, which are based on the conventional one -dimensional, two-layer model that comprises a film and a substrate, is known to be inaccurate for materials with high thermal effusivities because of the effect of two -dimensional heat flow, which is closely related to the longer thermal diffusion length in the substrate. If two samples with the same values of thermal effusivity have different values of heat capacity per unit volume, they have different values of thermal diffusivity as well as thermal diffusion length. Thus, the influences of the two-dimensional heat flow are different for the two samples. In this study, we developed a new calibration procedure that uses reference samples with known thermal effusivities. The values derived with this calibration procedure do not include the effect of heat capacity per unit volume on two-dimensional heat flow. However, the present measured values, which are calibrated from different values of heat capacity per unit volume of reference samples, almost agreed with the values provided in the literature. In this study, we demonstrated that this new procedure provides a relatively easy and practical method to calibrate a thermal microscope for measuring thermal effusivity. Hatta proposed that the heat capacity per unit volume at room temperature lies within a small range around $2 \times 10^{6}$ $\mathrm{Jm}^{-3} \mathrm{~K}^{-1}$ over a variety of solid materials [21]. His proposal also suggests that the uncertainty in the thermal effusivity value is small due to the difference in the heat capacity per unit volume; this is because the difference between the values of heat capacity per unit volume of solid materials at room temperature is small. In order to obtain better accuracy in the calculations and for further expansion in the measurement range of thermal effusivity, we propose a numerical calculation or analytical solution by considering the effects of the heat capacity per unit volume of the sample, which is closely related to the two-dimensional heat flow. This method developed by us enables to expand the measurement range of thermal effusivity by using a thermal microscope for materials with high thermal conductivity, such as intermetallic compounds, functionally graded materials, and metal -based composite materials.

\section{ACKNOWLEDGEMENTS}

Dr. Yo Tomota and Dr. Tetsuya Suzuki, Ibaraki University, Department of Engineering, provided us with functionally graded materials. Bethel Hudson Inst. Co., Ltd. provided guidance on the analysis of the experimental results and extended their cooperation throughout the study. We are extremely grateful for their assistance.

\section{NOMENCLATURE}

$\omega$ : Angular frequency of intensity modulation, $\mathrm{s}^{-1}$. 
$\delta$ : Phase lag of the temperature response to the heating laser, rad.

$\delta_{h}$ : Phase lag of heating laser to reference signal, rad.

$\delta_{p}$ : Phase lag of probe laser reflected from a sample to reference signal, rad.

$d$ : Film thickness, $\mathrm{m}$.

$\alpha_{f}$ : Thermal diffusivity of the film, $\mathrm{m}^{2} \mathrm{~s}^{-1}$.

$b_{f}$ : Thermal effusivity of the film, $\mathrm{Js}^{-0.5} \mathrm{~m}^{-2} \mathrm{~K}^{-1}$

$b_{s}$ : Thermal effusivity of the substrate, $\mathrm{Js}^{-0.5} \mathrm{~m}^{-2} \mathrm{~K}^{-1}$

$\tau_{f}$. Heat diffusion time over the film, s.

$\beta$ : Thermal effusivity ratio defined by $b_{\mathrm{s}} / b_{\mathrm{f}}$

$C$ : Specific heat capacity, $\mathrm{Jkg}^{-1} \mathrm{~K}^{-1}$

$\sigma:$ Standard deviation of uncertainty, $\mathrm{Js}^{-0.5} \mathrm{~m}^{-2} \mathrm{~K}^{-1}$

$D_{0}$ : Spatial resolution of measurement, $\mu \mathrm{m}$

$D_{1}$ : Thermal diffusion length, $\mu \mathrm{m}$

\section{REFERENCES}

[1] J. Opsal, A. Rosencwaig; J. Appl. Phys., 53 (1982), 6.

[2] A. Rosencwaig, J. Opsal, W. L. Smith, D. L. Willenborg; Appl. Phys. Lett., 46 (1985), 11.

[3] L. Pottier; Appl. Phys. Lett., 64 (1994), 13.

[4] F. Lepoutre, D. Balageas, Ph. Forge, S. Hirschi, J. L. Joulaud, D. Rochais, F. C. Chen; J. Appl. Phys., 78 (1995), 2208.

[5] S. Huxtable, D. G. Cahill, V. Fauconnier, J. O. White, J. -C. Zhao; Nat. Mater., 3 (2004), 298.

[6] R. M. Costescu, M. A. Wall, D. G. Cahill; Phys. Rev. B., 67 (2003), 054302.

[7] K. E. O’ Hara, X.-Y. Hu, D. G. Cahill; J. Appl. Phys., 90 (2001), 4852.

[8] N. Taketoshi, M. Ozawa, H. Ohta, T. Baba; AIP Conference Proceedings, Photoacoustic and Photothermal Phenomena. Tenth International Conference., 463 (1999), 315.

[9] N. Taketoshi, T. Baba, A. Ono; Thermal conductivity, 24 (1999), 289.

[10] T. Suzuki, A. Tani, N. Katakura, Y. Tomota, H. Hatori, H. Ohta; Netusyori, 42 (2002), 111.

[11] T. Yagi, N. Taketoshi, H. Kato; Physica C., 412-414 (2004), 1337.

[12] K. Hatori, N. Taketoshi, T. Baba, H. Ohta; Rev. Sci. Inst., 76 (2005), 4901.
[13] S. Ikeuchi, T. Yagi, H. Kato; J. Cryo. Soc. Jpn., 40 (2005), 335.

[14] H. Ohta, K. Hatori; Electric parts and materials, 6 (2005), 33.

[15] Y. Okamoto, J. Morimoto, K. Fukui, J. Saeki, T. Otuki; Electric parts and materials, 2 (2006), 39.

[16] T. Okamura, Y. Hattori, J. Ye; Japan Conf. Calorimetry Thermal Analysis Fukuoka Japan, 41 (2005), 20.

[17] Japan Thermophys. Prop. Soc.; "Thermophysical properties Handbook," p.23, p.24, p.29, p.264 (Yokendo LTD., Tokyo, 1990).

[18] JFCC, Referceram SN1 data sheet, lot.12

[19] N. Taketoshi, T. Yagi, T. Baba, A. Ono; $24^{\text {th }}$ Japan Symp. Thermophys. Prop. Okayama Japan, 24 (2003), A301, 243.

[20] H. Kafuku, Y. Tomota, M. Isaka, T. Suzuki; Mater. Metal. Trans., A33A (2002), 3235.

[21] I. Hatta; Thermo chemica Acta., 446 (2006), 176-179.

[Received Aug. 27, 2007, Accepted Feb. 12, 2008] 